Article

\title{
Against Game Studies
}

\author{
Alex Gekker \\ Media Studies, University of Amsterdam, 1012 XT Amsterdam, The Netherlands; E-Mail: a.gekker@uva.nl
}

Submitted: 1 June 2020 | Accepted: 20 August 2020 | Published: 6 January 2021

\begin{abstract}
The article explores the limitations of the current scholarly game studies (GS) field. Its central presuppositions are (1) that there are certain attributes broadly understood as "GS" by those writing in or adjacent to the field; (2) that those attributes are historically rooted in an attempt to disassociate videogames from other types of electronic (and later-digital) media; and that (3) the preconditions that have led to this split are currently moot. In the first section of this article, I elaborate on these presuppositions through reading GS as a historically rooted field, centred around the videogame artefact. Following, by examining the notion of being 'against' something in academic work, I move to my central claim for the article: that maintaining this conception of GS is counterproductive to the state of contemporary videogames scholarship and that adopting a post-dualistic and post-humanities stance will greatly contribute to the broadening of the field. I break down this claim into three separate threads. Ontologically, I show that videogames are much closer to non-videogames than they used to be. Methodologically, I point out how re-integrating methodologies from outside the field is crucial to address the complex phenomena evolved in and around gaming. Politically, I highlight the importance of games in contemporary digital culture and show how boundary-work and gatekeeping might harm the attempt to make game scholarship engage with larger political issues. The article concludes with suggestions for a more inclusive and intermingled vision for the field, focusing on the notion of play rather than games.
\end{abstract}

\section{Keywords}

game studies; play; methodology; post-humanities

\section{Issue}

This article is part of the issue "Games and Communication-Quo Vadis?" edited by Marko Siitonen (University of Jyväskylä, Finland), Felix Reer (University of Muenster, Germany) and Teresa de la Hera (Erasmus University Rotterdam, The Netherlands).

(C) 2021 by the author; licensee Cogitatio (Lisbon, Portugal). This article is licensed under a Creative Commons Attribution 4.0 International License (CC BY).

\section{Introduction: Tilting at Windmills}

Critiquing an entire academic field is a fool's errand. At best, one might point at some broad issues that are commonplace in any community of practice, academic or otherwise (cf. Mäyrä \& Sotamaa, 2017). At worst, the critique will end up as nothing more than a pedantic rant against a fast-moving target: After all, a scholarly field is rapidly changing and contains multitudes. What is "commonplace" or "central" to the field can disappear the next day. Why, then, author an article lashing at game studies as a whole, besides a vague hope of accruing many a-negative citations, in a perverse click-bait-like take on the academic game?

The following pages attempt to prove the endeavour worthwhile. The central presuppositions of this article are: (1) that there are certain attributes broadly understood as "Game Studies" (GS) by those writing in or adjacent to the field; (2) that those attributes are historically rooted in an attempt to disassociate videogames from other types of electronic (and later-digital) media; and that (3) the preconditions that have led to this split are currently moot. In the first section of this article, I elaborate on these presuppositions through reading GS as a particular historiography, rooted in both technical and disciplinary developments. Drawing on key texts that similarly grapple with the field, I present an historically rooted operational definition of GS. Following, I move to my central claim for the article: that maintaining this conception of GS is counter-productive to the state of the contemporary videogames scholarship. I break down this claim into three separate objections: ontological, 
methodological and political. The article concludes with (what I hope to be) a productive suggestion for a more inclusive and intermingled vision for the field, focusing on the notion of play rather than games.

Ultimately, this article can be read as a doomed project, a catch-22 of academic hot takes: I write it as someone familiar with GS yet more by way of flirtation than actual embeddedness in the field. I get invited each year to review DiGRA submissions, but never apply myself. On the one hand, I strongly believe that in order to mount a critique of the sorts presented below, one must have a somewhat external look on the field. On the other, to be able to even define the field and defend such critique requires an intimate level of detail available only to the most engaged insiders. The following is an attempt to reconcile this paradox.

\section{What's in a Name?}

GS can be understood as a "third wave" of research on games, after early anthropological research in the late 19th century and educational takes in the 1970's. Ushered in the early 2000's with the rise of gaming as popular pastime and establishment of key academic journals (Stenros \& Kultima, 2018). Originally envisioned as interdisciplinary field (Deterding, 2017) the scholars drawn to it across various domains have attempted to develop a coherent framework for studying games, drawing from stories, mechanics and the communities arising from them, all the while bringing together various ontologies and methodologies from their own fields. With this, Stenros and Kultima draw a comparison to the field of design research as 'a paradoxical task of creating an interdisciplinary discipline' (Stenros \& Kultima, 2018, p. 344, emphasis in original work). Over time, voices within the field grew to re-consider it to include non-digital games and adjacent phenomenon (Mäyrä \& Sotamaa, 2017), but as becomes apparent through several recent introspective works, it still skews heavily towards scholarship on a somewhat limited corpus of (mostly) digital games.

In recent years, several attempts have been made to gage the scope, make-up and topics of the field. Scientometric and bibliometric analysis of GS has been carried out using among others meta-data from key publication venues to detect topics and communities in the field (Melcer et al., 2015), the games and genres derived from top publications (Coavoux, Boutet, \& Zabban, 2017), longitudinal trends derived from broader co-citation and co-occurrence in GS articles (Martin, 2018) or the canon of games arising from this scholarship (Frome \& Martin, 2019). Parallel, surveys have been circulated to gage the self-perception and professional identity of those engaged in researching games (Mäyrä, Van Looy, \& Quandt, 2013; Quandt et al., 2015). Consistently, GS was shown to be as rather monolithic in terms of scope, genres and methods, with a strong emphasis on social science and humanities scholarship and separate from technical and cognitive studies of games, although oftentimes bridged to it by design approaches. To be clear: in many ways this is excellent, especially for an emerging discipline. GS arose with the promise to bring cohesion to studying games, and a (relatively) stable repertoire is a step in the right direction. However, as Deterding points out in his state-of-thefield analysis 'while GS were initially formed to be the umbrella interdiscipline of (digital) game research, they have become a subcommunity within game research' (Deterding, 2017, p. 531., emphasis in original work). He points out to several particular reasons to this, chiefly the exodus of Media, Communication and Psychology scholars to other venues due to career and publishing limitations. He refers to this as the "pyrrhic victory" of GS: by legitimising the scholarship on games, it made easier for academic to pursue game research in broader disciplines. Regardless, he stipulates that:

Game studies are today constituted by humanities, qualitative social sciences, and design scholars focused on games and play as cultural phenomena of meaning making, with homogenous epistemic cultures: some form of constructivism, pragmatism, or transformative critical theory, with a tendency toward qualitative or textual analysis. (Deterding, 2017 p. 533)

One particular aspect arising from studying the field is the emphasis on certain types of (commercial) gaming phenomena, particularly online games (Coavoux et al., 2017; Frome \& Martin, 2019; Martin, 2018). This potentially leads to a path dependence that pushes game scholars to focus on a limited number of highly-visible games, genres and related practices, limiting publishing opportunities to those lacking certain gaming capital (Coavoux et al., 2017). Consequently, a familiarity with this canon of games seems to be a requirement for active participation in the field. Deterding (2017) similarly suggests that one potential outcome of GS is that they will become akin to film studies in predominantly addressing the cultural meaning of games, limiting their epistemic and practical authority but embracing such position within the broader game research. Due to contemporary game landscape, as well as the range of phenomena that fall under the term 'game' (Stenros \& Kultima, 2018) this possibility might be even more limiting that previously imagined as the gap between established scholarship and current playing practices widens, particularly along race, gender and class divides. As Frome and Martin concur from their analysis of the GS canon:

Simply put, students who are not familiar with World of Warcraft will not fully understand more than a quarter of the articles in the field's two leading journals. The more students know World of Warcraft, the better they will be able to critically engage with the arguments put forth in articles citing that game, and 
the same is true for Tetris, Grand Theft Auto, and other highly cited "canonical" games.' (Frome \& Martin, 2019, p. 16).

Those parallel trends-the focusing of GS on cultural meanings and the reliance on a potentially exclusionary canon-are the key processes that serve as the foundation for the rest of this article's critique. Moreover, as identified by the Ludica research collective already more than a decade ago (Fron, Fullerton, Morie, \& Pearce, 2007) and reiterated ever since, this leads to a serious imbalance for women and PoC in terms of access to the scholarly field.

From its inception GS always had a progressive social justice streak and have done much in addressing and critiquing the inequalities of games culture when approaching in-built divides (Consalvo, 2007; Mortensen, 2018; Shaw, 2010, 2012), gender discrepancies (Beavis \& Charles, 2007; Cassell \& Jenkins, 2000; de Castell \& Skardzius, 2019), race (Everett \& Watkins, 2008; Gray, 2012), colonial legacies (López, de Wildt, \& Moodie, 2019; Mukherjee, 2015) and labour issues (Huntemann, 2013; Kerr, 2016; O’Donnell, 2014; Hammar et al. 2020). However, due to the narrowing described above and despite continuous attempts to open up the ranks, the centrality of certain digital games led to a dynamic of boundary-work (Gieryn, 1983; Star \& Griesemer, 1989) that can be prohibitive for newcomers and limit the influx of ideas. As Emma Vossen, academic and past editorin-chief of the popular scholarship website First Person Scholar writes in her autoethnographic take on the field:

When writing about games, I feel that I need to constantly make it clear that I am a lifelong gamer in a way I wouldn't feel the need to establish myself as a lifelong reader of Middle English texts, because my experience in games culture has taught me that if I don't establish myself as someone who has been gaming since childhood, I won't be taken seriously. Because of my gender, if I don't insist on my expertise-and even when I do-I will be assumed not to have it. I've been asked by male scholars and students if I've ever heard of World of Warcraft or Skyrim, yet as an English major no one has ever asked me if I've heard of Nabokov or Dickens. Game studies is unique in this way because it's part of games culture, but also because all game scholars are in some way gamers and therefore even while we study games and those who play them, we still replicate the problems of games culture within our own field and therefore within our own culture. (Vossen, 2018, p. 214)

One could argue, partially based on the empirical introspective research above, that not all GS people are gamers. But therein lies the paradox. Potentially, there exist those who might be participating in GS, but not defining themselves according to their affinity with the medium. In practice, they often find themselves outside of the boundaries of the field. The surveys have shown a surprisingly low diversity in approaches to games. Field participants played an average of one hour or more games each day, two thirds have self-identified as gamers and very few never played a game at all (Mäyrä et al., 2013; Quandt et al., 2015). While a survey through a GS mailing list has an obvious self-selection bias, it nonetheless points to what Vossen identifies above-game researchers are predominantly gamers. Bordering on the banal, this truism opens the possibility for inquiry-what does GS loses when, even today, its opening move hinges on a potentially uniform an exclusionary approach to games. My answer, which I will articulate through the rest of this article, is that we lose some of the potential in engaging with objects, phenomena and scholarship existing on the boundaries of games by focusing too much on dualistic ontologies such as what constitutes a game or not, and instead advocate for a "post-humanities" approach to GS (Pettman, 2019). The argument proceeds through examining what does it mean to be "against" something in academia. Establishing the boundaries of the critique, I then suggest that current moment makes games more alike to other range of media phenomena than different from them, arguing against the institutional exceptionalism of GS through three facets: ontologically, methodologically and politically.

\section{A Brief History of Against-Ing}

What does it mean to be against something, in academic parlance? In brief, it is to recognise a broad framework or concept that is routinely deployed in a community of practice and question its quotidian use. One of the earlier examples in contemporary scholarship is Susan Sontag's (1966/2001) Against Interpretation. In it, the essayist and writer rejects the primacy of intellectual engagement with visual and written art, prevalent among her contemporaries. She points that the art world has disallowed mimetic representation notions ("art is what is depicted in art") yet nonetheless kept its foundation belief in the interpretative ones ("art is what can be understood from art"). To her, this rings as a fallacy that prioritises readings of content over the experiential engagement of individual encounter with the text. Consecutively, she writes, '[w] hatever it may have been in the past, the idea of content is today mainly a hindrance, a nuisance, a subtle or not so subtle philistinism' (Sontag, 1966, 2001, p. 2). Rejecting interpretation is one thing-but rejecting the idea of content? The answer, of course, is that Sontag revolts not against the notion of content itself, but the prioritization of well-accepted interpretive frameworks (particularly Marxist and Freudian) that neuter the artwork from its revolutionary potential to 'make us nervous' since 'by reducing the work of art to its content and then interpreting that, one tames the work of art. Interpretation makes 
art manageable, comfortable' (Sontag, 1966, 2001, p. 5). Similarly, I recognise the existence of games studies as a field aimed at engaging with the complicated relations between videogames and various aspects of culture and society, but I warn against it becoming an interactive variant of film studies with limited ability to act politically outside of its academic circles.

In his excellent provocation Fuck Nuance, sociologist Kieran Healy similarly rallies against what he calls 'Actually Existing Nuance,' defined as:

The act of making-or the call to make-some bit of theory "richer" or "more sophisticated" by adding complexity to it, usually by way of some additional dimension, level, or aspect, but in the absence of any strong means of disciplining or specifying the relationship between the new elements and the existing ones. (Healy, 2017, pp. 119-120)

Healy identifies the rise of nuance as a specific phenomenon in contemporary sociology and traces its start to the 1990s through a word analysis of leading sociological journals. He links it to several different trends in social theory, namely prioritising the empirical; cementing specific theoretical frameworks as a defence from rebuttal; and claiming that social realities cannot be reduced to theory. Some of those trends are also present in GS-particularly the second kind-seeing how many of the field's formalists' keep introducing new frameworks and/or typologies to be applied on selected games. However, my goal here is not to categorise the various moves performed by disciplinary scholars as Healy does. Rather, taking a cue from his historicising of nuance, I suggest that the current platitudes of GS are the product of changes in the field and its object of study, rather than some inherent flaw or a primordial sin. Here I am also influenced by inequalities sociologist Jo Littler's Against Meritocracy (2017). Combining a genealogical analysis of the term with a take on its current political deployment, Littler treats the meritocracy discourse as an urgent issue facing society that requires a strategic dissection. While seemingly less crucial, GS too have certain urgency, as games become the frontline of culture and political wars (Chess \& Shaw, 2015; MacDonald, 2019). Therefore, my analysis here is never meant to critique or call-out a specific author, school of thought, or research direction. Rather I strive to illuminate contemporary developments within the field and their potential limitations.

This article is therefore far from being a scathing teardown of GS, the disciplinary presuppositions of those coming into it or the foundational theories on what games are or their role in the world (Aarseth, 2001; Abt, 1970; Caillois \& Halperin, 1955; Huizinga, 1938; Juul, 2005; Murray, 1997). It is thus not written in the way of Feyerabend's seminal Against Method (1993), demolishing its every belief and common knowledge and arguing for epistemological anarchism. Quite the opposite, I welcome and cherish established method- ologies and other "ways of doing" but find the current common toolset (identified by Deterding above) somewhat limiting. Still often derived from binaries as ludology/narratology, game/player, intent/meaning, to name but a few, such methodologies can regrettably function as a disciplining tool for who is-or is not-part of the field or which scholarship is accepted (Frasca, 2003; Voorhees, 2013). Let us then move beyond binaries, and instead examine the way those can be synthesised (Del Casino \& Hanna, 2006). Specifically, I wish to promote what Escobar (2018) calls a posdualist ontology, one centred less of defining the boundaries of objects (games, in this case) and instead imagining them as continuous across a single ontological plane, with permeable borders.

One of the most famous (games) articles addressing binary thinking is Miguel Sicart's (2011) Against Procedurality. It launched a sustained critique of what Sicart perceived to be a practice of ascribing games' meaning primarily to gaps left there by designers for the players to act without agency. The article has ultimately resulted in many back-and-forths followed by an ongoing debate on the agency of designers vis-à-vis that of player. Already in his next major work, Sicart resolves the seemingly opposed meaning and incorporates the notion of procedurality that he was "against" into his analysis of toys and their operant conditions as play-instruments (Sicart, 2014). This type of postdualist ontology is also indicative of the growing line of hybrid thinking that Dominic Pettman (2019) refers to as the "post-humanities," or the intermingling between various forms of humanities and social sciences analyses to better account for the material shift in media technologies constituting life itself (cf. Deuze, 2012). Those two "post-" approaches will be examined through three separate objections to certain aspects of GS.

\section{Ontologically: Resisting the Game Boundary}

The initial work on GS was to show how games were new, different, other, 'combin[ing] the aesthetic and the social in a way the old mass media, such as theatre, movies, TV shows and novels never could' (Aarseth, 2001 , p. 1). Such proclamation were quite common around novel digital objects in those years, in what new media historian Michael Stevenson (2016) defines to be a rupture-rather than continuous-approach. In other words, entrepreneurs, journalists or scholars alike were eager to establish their own practices as new and distinct, breaking with historical continuities. It is therefore not at all surprising that early game scholars found the need to ascertain a field which also seemed to them 'very open to intrusions and colonisations from the already organized scholarly tribes. Resisting and beating them is the goal of our first survival game' (Eskelinen, 2001, p. 175). And so, much of what GS were originally about came from a sense of historical urgency to define and defend a field unlike many others, in a trajectory similar to the 
constant oppositional re-definition that occurs in social sciences (Abbott, 2001). One clear example is in the need to define what constitutes a game or not. Almost two decades after its inception, and still:

Often game studies should actually be called digital game studies....This may seem like a minor semantic quibble, but as our papers are filled with totalizing statements about "games," we too easily start to believe our own overly broad generalization. Games can be, and are, multiple. (Stenros \& Kultima, 2018, p. 346)

Following, I want to suggest that the current media ecosystem has rendered the point moot, as the rapid digitalisation alongside the proliferation of gameplay elements in non-games have left the objects of research extremely porous (Deterding, 2015). Many the conditions that made the game/no-game distinction possible (if they ever existed) - separate physical objects, autotelic gaming devices, clear division into genres and specialised knowledge-are disappearing. From the proliferation of gamification, to the playful role of social media, to the growing ephemerality of goods and services that include gaming software and hardware-drawing clear boundaries is no longer possible. Stenros and Kultima, for example, give examples of game streaming and spectatorship that 'stand in stark contrast to the neat ontologies' which were previously common in GS (Stenros \& Kultima, 2018, p. 347). Moreover, as those processes accelerate, I venture that the question of "what is a game and where are its boundaries" matters less than "what do game-like objects mean for the individual and society." Here I want to focus on the case of Bandersnatch, the interactive choose-your-own-adventure episode of the dystopian anthology Black Mirror (Slade, 2018).

Presented as a stand-alone offering to accommodate for its unique features, Black Mirror: Bandersnatch is a in interactive tale about game development in the form that resembles that of a game. The story follows the misadventures of a young game programmer in the 1980s, who begins to suspect his actions are controlled by sinister external force. This is a meta-commentary as well as a plot point, since the viewer is able to interject in key decision points to choose for the protagonists and influence outcomes. The film has sparked popular interest as well as scholarly one: an initial Google Scholar search revealed more than 300 publications on the film since its release. Bandersnatch scholarship is understandably not limited to games journals. It is used: for an exploration of agency, choice and trauma from philosophical and psychological perspectives (Lay \& Johnson, 2019; McSweeney \& Joy, 2019); in empirical research on the potential for various interfaces (Nascimento et al., 2019; Roth \& Koenitz, 2019); as a mediation over the potential of data extraction and invasive product placement (Elnahla, 2019); a threat for hacking and data theft of the choices made by the viewers (Mitra, Vairam,
Slpsk, Chandrachoodan, \& Kamakoti, 2019) or within Netflix's overall goals and business models (Raustiala \& Sprigman, 2019).

Ultimately, this is where Pettman's ideas are helpful. To him, the major shift that occurrs in researching various forms of digital media moves from epistemology (in our case, the boundary of defining games) to ontology (how do games, as amalgamated entities, exact influence on the world, including on the scholars studying them). Thus:

[I]f the posthuman is the name we give to the recognition that the human has always been an inherently technical creature, then the post-humanities registers the fact that we are not so much the rational animal, as the mediated animal. Everything we do, think, and communicate is always already mediated. Hence the new global interest in media studies, as something that goes far beyond the analysis of the structures and contents of communications and entertainment industries, to the very heart of our own, semiotically saturated, being. (Pettman, 2019)

Understanding Bandersnatch as a primarily mediated object does not eliminate its potential heritage in games-or interactive/ergodic literature studies. Instead, it offers scholars the possibility of developing cross-disciplinary middle-range theories or boundary objects, advocated by Deterding, as one way to widen GS again. Specifically, it allows to bypass the notion of what is - or not-a game by adopting a perspective of "be[ing] "the species without qualities": a creature with no clear defining feature, other than its deep need to find a stable definition and raison d'etre for itself' (Pettman, 2019). Approaching such a fuzzy research object requires a reconsideration of our tools as well.

\section{Methodologically: Examining the Tools of the Trade}

How do we go about researching games? With the seeming narrowing of the field identified previously, in this section I wish to interrogate questions of methodology, both in the sense of approaches to how analyse games, and in the selection of games to analyse. After all, pointing to the lack of representation of sports and dance games in the GS despite their popularity in broader public, Coavoux et al. (2017) contend that:

[A]s in any field of research, especially research on culture or arts, the personal tastes of researchers in GS matter in the choice of research objects. However, these personal tastes are not only a matter of individual preferences but are also socially distributed. (p. 574)

Therefore, when examining the current state of GS methodologies, one must be mindful of the way messiness, flux and unclear object boundaries (Akrich, 1992) 
interact with game researchers' path dependence and may ultimately lead to a repetition in the shape and trajectory of existing scholarship. My call in this section thus follows similar ones from prominent GS scholars to abandon rigid definitions and instead conceive of games as an assemblage or a mess (Bogost, 2009; Taylor, 2009). My point of difference, however, is in paying closer attention to what actually constitutes as tools for GS, and how those tools themselves change under the altering conditions of gaming.

The promise of GS in postdualistic and posthumanities approach is in the ability to:

Pay special attention to our relationship to relationships; including and especially the relationship to our tools (which themselves are conscientiously helping to reveal new relationships, as well as often rendering older relationships - say, with viruses or carbonin a new light). (Pettman, 2019)

In other words, I propose taking a (new-)materialist approach to the examination of the processes that lead to the formation of conditions to studying games in one way or the other, moving beyond the ontological traps discussed in the previous section. While Deterding (2017) suggests design focus to expand GS beyond its current scope, Stenros and Kultima (2018) warn that the notion of design is perhaps as multifaceted as games themselves, and caution against the potential loss of context when integrating with game research beyond GS. I agree with them and argue that we can instead move diagonally-re-integrating new directions from media, communications or psychology studies in a the same way it was done during the field's establishment, and thus also potentially countering the 'pyrrhic victory' described by Deterding. Importantly, doing so requires a re-examination of what has changed in the methodologies and epistemologies of those original disciplines, for example the move of media studies away from content and towards infrastructural analysis (Pettman, 2019; Plantin, Lagoze, Edwards, \& Sandvig, 2018). In other words, reflecting on the historicity of GS alongside the historicity of the disciplines it moved away from. To demonstrate, let's examine the necessary toolsets to discuss the case of the CSGO Lotto.

In 2017, Trevor "TmarTn" Martin and Thomas "Syndicate" Cassell avoided a US Federal Trade Commission (FTC) fine for their promotion of a gambling site, which they secretly owned (FTC, 2017). The two are Counter Strike: Global Offensive (CS:GO) esports players, youtubers and streamers. From 2015 onwards, as part of their online activity on multiple platforms (mainly: Twitch, YouTube and Twitter) they began promoting a website called "CSGO Lotto." There, users could gamble on the outcome of professional CS:GO events for the chance to acquire weapon skins (cosmetic upgrades). This practice is borderline legal, as many countries forbid unregulated gambling in real money (as opposed to virtual goods) and the thriving CS:GO marketplace allows for conversion of skins into currency, as the case of a purchased rifle skin for $\$ 61,000$ (Rose, 2018). The main issue in the case of Martin in Cassell, however, was that they owned this website and payed fees to other gaming celebrities as part of a "influencer programme" to promote it, without disclosing this connection to their audiences. Despite all this, FTC decided to settle with the two in their 'First-Ever Complaint Against Individual Social Media Influencers' (FTC, 2017) while also using this case to create and enforce clear influencers' self-disclosure rules.

To understand the case, one must explore the game itself, the (modding) community around it, the decisions made by Valve (the games' creator but also de-facto monopoly in PC gaming), YouTube and streaming culture and the political economy of influencers, at the very least (Abidin, 2016; Burwell \& Miller, 2016; Joseph, 2018; Marwick, 2015; Taylor, 2018). These are not only cumulative aspects, but also mutually-entangled ones: a change performed by Valve regarding visibility of external CS:GO gambling sites on its Steam service might result in galvanising the community by a gaming micro-celebrity, which then manifests on other external platforms. All this requires a keen look into the way those various platforms normalise behaviours (Gillespie, 2017), but also how they influence each other in instances of cross-platformisation (Burgess \& Matamoros-Fernández, 2016) and the people engaged with them. Consequently, the analysis will strongly benefit from a post-humanities approach that focuses on the "tool-relationship" aspects of all the entities above towards users, players, and towards each other. Such approach would further unashamedly borrow from fields and topics beyond the ones identified as common to GS (Coavoux et al., 2017; Martin, 2018)

\section{Politically: Facing Gaming's Future}

In her feminist critique Vossen (2018, p. 220) diagnoses a perceived "unseriousness" of GS's subject matter that leads to a defensive stance from those engaged in researching games. I would further argue that for people outside game research, games-and their audiencesare also perceived as very toxic (Mortensen, 2018). It is this combined view on something as silly and/or harmful that leads game scholars to defend games as legitimate medium/hobby to external audiences while mostly detailing its cultural and political flaws internally.

Part of this double position is the same territoriality that Aarseth (2001) and Eskelinen (2001) sought to promote in early (and since revised) writings: the field feels pulled into multiple directions. I speculate that some of the more experienced scholars might be somewhat resentful towards the domestication and normalisation of videogames as research objects, due to the processes described by Deterding (2017). They had to overcome resistance in the broader academic commu- 
nity and carve a field around this new medium, only to see it become co-opted by other fields (often in a somewhat negative capacity and by those who don't seem to understand games at all). However as outlined throughout this article, this has to do as much with the changes that occurred within the gaming world and parallel "pyrrhic victory" of GS, as with desire of others to "colonise" it. Perhaps, in the spirit of the post-humanities, GS should recognise that they are part of the broader changing digital landscape where 'we can no longer assume we all agree, or even instinctively know, what counts as "media," and where "[e]verything can be considered an enabler of mediation (even objects or phenomena that seem to stubbornly refuse or even discourage communication; such as black boxes or censorship regimes)' (Pettman, 2019).

Adopting this flux and integrating more from other fields into GS might ultimately be the best way to academically represent games, their communities and realities in a time where they are so embroiled in various broader issues. One can only imagine how different the academic response could have been and what actions could be pre-emptively done if GamerGate would not have been perceived as a "games" issue, but rather through a broader societal, political and media upheaval (Wu, 2020). The predominantly female leadership (and other women/PoC members) of DiGRA at that time suffered horrendous abuse due to their seeming association with the "contaminating" of games. Yet the phenomenon has been rarely discussed or acted upon outside of game scholarship and gaming press, and only later was recognised as the proto-alt-right in the making (Lees, 2016). If we presume gaming to be the canary in the mine of contemporary digital culture, who knows what other fascinating-but also dangerous-phenomena lie in its crosshairs yet currently dismissed by more established and powerful fields? Unfortunate as it is, GS simply cannot afford not to stubbornly engage with those other disciplines.

\section{Conclusions: Playing Together}

This article followed a line of critics that identified a certain narrowing of existing GS as a scholarly field and thus potential exclusion of those lacking cultural capital to participate. While trying not to paint with too broad of a brush, I nonetheless attempted to identify three general lacking aspects of GS at large and offer some directions on addressing them.

To be clear, I am far from the only one to make those observation. Much of this work is already found in GS discussions and journals, or in broader media and communications publications. Several recent special issues come to mind that take games through cross-platform and intersectional lenses as a fluid object requiring diverse methodologies. The Ludic Economies issue of Games and Culture (Giddings \& Harvey, 2018), the Contested Formations in Television \& New Media (de Peuter \&
Young, 2019) or the two special issue co-edited by Sonia Fizek on automation for Journal of Gaming and Virtual Worlds (Fizek \& Rautzenberg, 2018) and the seemingly promising upcoming Laborious Play and Playful Work issue for the Digital Culture and Society. Geography scholars have been similarly using games to build new theories on post-phenomenological relations with space (Ash, 2012) to re-examine domesticity (Pink, Hjorth, Horst, Nettheim, \& Bell, 2018), or to make sense of ruins and landscapes (Fraser, 2016). Games are used in media studies to reflect on wearable technology (Wilmott, Fraser, \& Lammes, 2018), platforms (Nieborg \& Poell, 2018; Plantin et al., 2018) or market commodities (Hamari, 2011; Nieborg, 2015). I wish to emphasise again and again that nothing makes the above titles "better" than other game research. Rather, those are some publications that go beyond the established ontologies and methodologies of GS and instead address their messy entanglements with other complicated issues of contemporary media-life.

Finally, we must ask, if not GS-then what? It is always easy to dismantle without offering a constructive alternative (Latour, 2004). My answer is not in the least original and has been touted one way or another by many scholars beforehand: focus on play instead of games (Mäyrä et al., 2015). While some in the field already use the combined (and cumbersome) Games and Play Studies, I would urge to drop the first part altogether. This requires re-examining the relations of GS with the field that sprung from the "second wave" of game research (Stenros \& Kultima, 2018) as exemplified in the Association of the Study of Play (TASP). While outside the scope of this article, this association is similarly approaching questions of (anthropological and behavioural) play, as can be seen in its recent Celebrating 40 Years of Play Research special collection (Patte, Sutterby, \& Johnson, 2016). The revised name would incorporate videogames, but also board games, interactive stories, table-top, esports, sports (games) and many other activities that are not easily classified as games but currently share some aspects or digital infrastructure (social media or Tinder come to mind), moving away from binary ontologies and towards fluid and inclusive ones. And finally and above all, this would somewhat lower the perceived barrier for newcomers who do not see themselves as gamers or game scholars (or-unfortunately-are not allowed to be seen as such), opening the field for novel ideas, faces and ways. If, as Zimmerman (2015) famously claimed, we are entering a "ludic century," then surely, we need all the help we can get to make sense of it.

\section{Acknowledgments}

I wish to thank the participants of the 2019 ECREA Games Section Symposium in Rotterdam who provided valuable feedback on an early presentation version of this article. To the organisers who further encouraged me to submit 
to this special issue. To Joleen Bloom who provided a crucial perspective during the re-writing of the article and to Sam Hind, Emma Fraser and Sybille Lammes for their insightful remarks.

\section{Conflict of Interests}

The author declares no conflict of interests.

\section{References}

Aarseth, E. J. (2001). Computer game studies, year one. Game Studies, 1(1), 1-15.

Abbott, A. D. (2001). Chaos of disciplines. Chicago, IL: University of Chicago Press.

Abidin, C. (2016). Visibility labour: Engaging with influencers' fashion brands and \#OOTD advertorial campaigns on Instagram. Media International Australia, 161(1), 86-100. https://doi.org/10.1177/ $1329878 \times 16665177$

Abt, C. C. (1970). Serious games. New York, NY: The Viking Press.

Akrich, M. (1992). The de-scription of technical objects. In W. E. Bijker \& J. Law (Eds.), Shaping technology/building society (pp. 205-224). Cambridge, MA: The MIT Press.

Ash, J. (2012). Technology, technicity, and emerging practices of temporal sensitivity in videogames. Environment and Planning $A, 44(1), 187-203$. https://doi. org/10.1068/a44171

Beavis, C., \& Charles, C. (2007). Would the "real" girl gamer please stand up? Gender, LAN cafés and the reformulation of the "girl" gamer. Gender \& Education, 19(6), 691-705. https://doi.org/10.1080/ 09540250701650615

Bogost, I. (2009). Videogames are a mess. Paper presented at the Digtial Games Research Association (DiGRA) 2009 conference, Uxbridge, UK. Retrieved from http://bogost.com/writing/videogames_are_a_mess

Burgess, J., \& Matamoros-Fernández, A. (2016). Mapping sociocultural controversies across digital media platforms: One week of \#gamergate on Twitter, YouTube, and Tumblr. Communication Research and Practice, 2(1), 79-96. https://doi.org/10.1080/22041451. 2016.1155338

Burwell, C., \& Miller, T. (2016). Let's play: Exploring literacy practices in an emerging videogame paratext. E-Learning and Digital Media, 13(3/4), 109-125. https://doi.org/10.1177/2042753016677858

Caillois, R., \& Halperin, E. P. (1955). The structure and classification of games. Diogenes, 3(12), 62-75. https://doi.org/10.1177/039219215500301204

Cassell, J., \& Jenkins, H. (Eds.). (2000). From Barbie to Mortal Kombat: Gender and computer games. Cambridge, MA: The MIT Press.

Chess, S., \& Shaw, A. (2015). A conspiracy of fishes, or, how we learned to stop worrying about \#gamergate and embrace hegemonic masculinity. Journal of Broadcasting \& Electronic Media, 59(1), 208-220. https://doi.org/10.1080/08838151.2014.999917

Coavoux, S., Boutet, M., \& Zabban, V. (2017). What we know about games: A scientometric approach to game studies in the 2000s. Games and Culture, 12(6), 563-584. https://doi.org/10.1177/ 1555412016676661

Consalvo, M. (2007). Cheating: Gaining advantage in videogames. Cambridge, MA: The MIT Press.

de Castell, S., \& Skardzius, K. (2019). Speaking in public: What women say about working in the video game industry. Television \& New Media, 20(8), 836-847. https://doi.org/10.1177/1527476419851078

de Peuter, G., \& Young, C. J. (2019). Contested formations of digital game labor. Television \& New Media, 20(8) 747-755. https://doi.org/10.1177/ 1527476419851089

Del Casino, V., \& Hanna, S. P. (2006). Beyond the 'binaries': A methodological intervention for interrogating maps as representational practices. ACME: An International E-Journal for Critical Geographies, 4(1), 34-56.

Deterding, S. (2015). The ambiguity of games: Histories and discourses of a gameful world. In S. P. Walz \& S. Deterding (Eds.), The gameful world: Approaches, issues, applications (pp. 23-64). Boston, MA: The MIT Press.

Deterding, S. (2017). The pyrrhic victory of game studies: Assessing the past, present, and future of interdisciplinary game research. Games and Culture, 12(6), 521-543. https://doi.org/10.1177/ 1555412016665067

Deuze, M. (2012). Media life (1st ed.). Cambridge and Malden, MA: Polity.

Elnahla, N. (2019). Black mirror: Bandersnatch and how Netflix manipulates us, the new gods. Consumption Markets \& Culture, 23(5), 506-511. https://doi.org/ 10.1080/10253866.2019.1653288

Escobar, A. (2018). Designs for the pluriverse: Radical interdependence, autonomy, and the making of worlds. Durham: Duke University Press Books.

Eskelinen, M. (2001). Towards computer game studies. Digital Creativity, 12(3), 175-183. https://doi.org/ 10.1076/digc.12.3.175.3232

Everett, A., \& Watkins, C. (2008). The power of play: The portrayal and performance of race in video games. In K. Salen (Ed.), The ecology of games: Connecting youth, games, and learning (pp. 141-166). Cambridge, MA: The MIT Press.

Federal Trade Commission. (2017, September 7). CSGO lotto owners settle FTC's first-ever complaint against individual social media influencers. Federal Trade Commission. Retrieved from https://www.ftc.gov/ news-events/press-releases/2017/09/csgo-lottoowners-settle-ftcs-first-ever-complaint-against

Feyerabend, P. (1993). Against method (3rd ed.). London and New York, NY: Verso. (Original work published 1975) 
Fizek, S., \& Rautzenberg, M. (2018). The work of game in the age of automation. Journal of Gaming \& Virtual Worlds, 10(3), 197-201. https://doi.org/10.1386/ jgvw.10.3.197_2

Frasca, G. (2003). Ludologists love stories, too: Notes from a debate that never took place. Paper presented at Digtial Games Research Association (DiGRA) conference 2003: Level Up, Utrecht, Netherlands. Retrieved from http://www.digra.org/wp-content/ uploads/digital-library/05163.01125.pdf

Fraser, E. (2016). Awakening in ruins: The virtual spectacle of the end of the city in video games. Journal of Gaming \& Virtual Worlds, 8(2), 177-196. https:// doi.org/10.1386/jgvw.8.2.177_1

Frome, J. H., \& Martin, P. (2019, August 7). Describing the game studies canon: A game citation analysis. Paper presented at the Digital Games Research Association (DiGRA) Conference 2019: Game, Play and the Emerging Ludo Mix, Kyoto, Japan. Retrieved from http://www.digra.org/digital-library/ publications/describing-the-game-studies-canon-agame-citation-analysis

Fron, J., Fullerton, T., Morie, J. F., \& Pearce, C. (2007). Playing dress-up: Costumes, roleplay and imagination. Paper presented at Philosophy of Computer Games Conference, University of Wales, Newport, UK. Retrieved from http://gamephilosophy.org/ wp-content/uploads/confmanuscripts/pcg2007/ Pearce_PaperPCG2007.pdf

Giddings, S., \& Harvey, A. (2018). Introduction to special issue ludic economies: Ludic economics 101. Games and Culture, 13(7), 647-651. https://doi.org/ $10.1177 / 1555412018755912$

Gieryn, T. F. (1983). Boundary-work and the demarcation of science from non-science: Strains and interests in professional ideologies of scientists. American Sociological Review, 48(6), 781. https://doi.org/10.2307/ 2095325

Gillespie, T. (2017). Governance of and by platforms. In J. Burgess, A. E. Marwick, \& T. Poell (Eds.), The Sage handbook of social media (pp. 254-278). Thousand Oaks, CA: Sage.

Gray, K. L. (2012). Deviant bodies, stigmatized identities, and racist acts: Examining the experiences of AfricanAmerican gamers in Xbox Live. New Review of Hypermedia and Multimedia, 18(4), 261-276. https://doi. org/10.1080/13614568.2012.746740

Hamari, J. (2011). Perspectives from behavioral economics to analyzing game design patterns: Loss aversion in social games. Paper presented at the CHI2011 conference (Social games workshop), Vancouver, Canada. Retrieved from http://www.researchgate. net/profile/Juho_Hamari

Healy, K. (2017). Fuck nuance. Sociological Theory, 35(2), 118-127. https://doi.org/10.1177/073527511 7709046

Nascimento, T. H., Nunes, F. A. A. D. M., Vieira, M. A., Felix, J. P., Mombach, J. G., de Campos, L. M. C., . . \& \& da Costa, R. M. (2019). Using smartwatches as an interactive movie controller: A case study with the Bandersnatch movie. In V. Getov, J.-L. Gaudiot, N. Yamai, S. Cimato, M. Chang, Y. Teranishi, ... S. Puri (Eds.), Processings 2019 IEEE 43rd Annual Computer Software and Applications Conference (COMPSAC) (pp. 263-268). Piscataway, NJ: IEEE. https://doi.org/ 10.1109/COMPSAC.2019.10217

Hammar, E. L., Wildt, L. de, Mukherjee, S., \& Pelletier, C. (2020). Politics of Production: Videogames 10 years after Games of Empire. Games and Culture. https:// doi.org/10.1177/1555412020954996

Huizinga, J. (1938). Homo ludens: Proeve eener bepaling van het spel-element der cultuur [Homo ludens: A study of the play-element in culture]. Amsterdam: Amsterdam University Press.

Huntemann, N. B. (2013). Women in video games: The case of hardware production and promotion. In $\mathrm{N}$. B. Huntemann \& B. Aslinger (Eds.), Gaming globally: Production, play, and place (pp. 41-57). New York, NY: Palgrave Macmillan US. https://doi.org/10.1057/ 9781137006332_3

Joseph, D. J. (2018). The discourse of digital dispossession: Paid modifications and community crisis on steam. Games and Culture, 13(7), 208-233. https:// doi.org/10.1177/1555412018756488

Juul, J. (2005). Half-real: Video games between real rules and fictional worlds. Cambridge, MA: The MIT Press.

Kerr, A. (2016). Global games: Production, circulation and policy in the networked era (1st ed.). London and New York, NY: Routledge.

Latour, B. (2004). Why has critique run out of steam? From matters of fact to matters of concern. Critical Inquiry, 30(2), 225-248. https://doi.org/10.1086/ 421123

Lay, C., \& Johnson, D. K. (2019). Bandersnatch, a choose-your-own philosophical adventure. In David Kyle Johnson and William Irwin (Eds.), Black Mirror and philosophy: Dark Reflections (pp. 197-238). Hoboken, NJ: John Wiley \& Sons. https://doi.org/ 10.1002/9781119578291.ch20

Lees, M. (2016, December 1). What gamergate should have taught us about the "alt-right." The Guardian. Retrieved from https://www.theguardian.com/ technology/2016/dec/01/gamergate-alt-right-hatetrump

Littler, J. (2017). Against meritocracy: Culture, power and myths of mobility. London: Routledge.

López, L., de Wildt, L., \& Moodie, N. (2019). 'I don't think you're going to have any aborigines in your world': Minecrafting terra nullius. British Journal of Sociology of Education, 40(8), 1037-1054. https://doi.org/ 10.1080/01425692.2019.1640596

MacDonald, K. (2019, May 9). We've seen Carl Benjamin's rank misogyny before: Remember gamergate? The Guardian. Retrieved from https://www. theguardian.com/commentisfree/2019/may/09/ gamergate-carl-benjamin-ukip-mep 
Martin, P. (2018). The intellectual structure of game research. Game Studies, 18(1). Retrieved from http:// gamestudies.org/1801/articles/paul_martin

Marwick, A. E. (2015). Instafame: Luxury selfies in the attention economy. Public Culture, 27(1(75)), 137-160. https://doi.org/10.1215/08992363-27983 79

Mäyrä, F., Lammes, S., Deterding, S., Giddings, S., Consalvo, M., Mortensen, T. E., . . . Jorgensen, K. (2015). From game studies to studies of play in society: A panel. Paper presented at the Digital Games Research Association (DiGRA) 2015: Diversity of Play: GamesCultures-Identities, Lüneburg, Germany. Retrieved from https://fransmayra.fi/2015/05/15/panel-fromgame-studies-to-studies-of-play-in-society

Mäyrä, F., \& Sotamaa, O. (2017). Need for perspective: Introducing the special issue "Reflecting and Evaluating Game Studies." Games and Culture, 12(6), 495-498. https://doi.org/10.1177/155541201 6672780

Mäyrä, F., Van Looy, J., \& Quandt, T. (2013). Disciplinary identity of game scholars: An outline. In Proceedings Digital Games Research Association, Proceedings. Paper presented at the Digital Games Research Association (DiGRA 2013). Retrieved from http://hdl. handle.net/1854/LU-4225122

McSweeney, T., \& Joy, S. (2019). Change your past, your present, your future? Interactive narratives and trauma in Bandersnatch (2018). In T. McSweeney \& S. Joy (Eds.), Through the Black Mirror: Deconstructing the side effects of the digital age (pp. 271-284). Cham: Springer. https://doi.org/10.1007/978-3-03019458-1_21

Melcer, E. F., Nguyen, T.-H. D., Chen, Z., Canossa, A., ElNasr, M. S., \& Isbister, K. (2015). Games research today: Analyzing the academic landscape. Paper presented at Proceedings of the 10th International Conference on the Foundations of Digital Games (FDG 2015), Pacific Grove, CA.

Mitra, G., Vairam, P. K., Slpsk, P., \& Chandrachoodan, N., \& Kamakoti, V. (2019). White mirror: Leaking sensitive information from interactive Netflix movies using encrypted traffic analysis. In Proceedings of the ACM SIGCOMM 2019 Conference Posters and Demos (pp. 122-124). Beijing: Association for Computing Machinery. https://doi.org/ 10.1145/3342280.3342330

Mortensen, T. E. (2018). Anger, fear, and games: The long event of \#GamerGate. Games and Culture, 13(8), 787-806. https://doi.org/10.1177/15554120 16640408

Mukherjee, S. (2015). The playing fields of empire: Empire and spatiality in video games. Journal of Gaming \& Virtual Worlds, 7(3), 299-315.

Murray, J. H. (1997). Hamlet on the holodeck: The future of narrative in cyberspace. New York, NY: Free Press.

Nieborg, D. B. (2015). Crushing candy: The free-to-play game in its connective commodity form. Social
Media+ Society, 1(2). https://doi.org/10.1177/ 2056305115621932

Nieborg, D. B., \& Poell, T. (2018). The platformization of cultural production: Theorizing the contingent cultural commodity. New Media \& Society, 20(11), 4275-4292. https://doi.org/10.1177/ 1461444818769694

O'Donnell, C. (2014). Developer's dilemma: The secret world of videogame creators. Cambridge, MA: The MIT Press.

Patte, M. M., Sutterby, J. A., \& Johnson, J. E. (2016). Celebrating 40 years of play research: Connecting our past, present, and future. Lanham, MD: Hamilton Books. Retrieved from http://ebookcentral. proquest. com/lib/uvanl/detail.action?doclD $=4658772$

Pettman, D. (2019, April 23). The species without qualities: Critical media theory and the posthumanities. B2O. Retrieved from http://www.boundary2.org/ 2019/04/the-species-without-qualities-criticalmedia-theory-and-the-posthumanities

Pink, S., Hjorth, L., Horst, H., Nettheim, J., \& Bell, G. (2018). Digital work and play: Mobile technologies and new ways of feeling at home. European Journal of Cultural Studies, 21(1), 26-38. https://doi.org/ 10.1177/1367549417705602

Plantin, J.-C., Lagoze, C., Edwards, P. N., \& Sandvig, C. (2018). Infrastructure studies meet platform studies in the age of Google and Facebook. New Media \& Society, 20(1), 293-310. https://doi.org/10.1177/ 1461444816661553

Quandt, T., Van Looy, J., Vogelgesang, J., Elson, M., Ivory, J. D., Consalvo, M., \& Mäyrä, F. (2015). Digital games research: A survey study on an emerging field and its prevalent debates. Journal of Communication, 65(6), 975-996. https://doi.org/10.1111/jcom.12182

Raustiala, K., \& Sprigman, C. J. (2019). The second digital disruption: Streaming and the dawn of data-driven creativity. New York University Law Review, 94(6), 1555-1622.

Rose, V. (2018, January 30). CS:GO fan drops $\$ 61 \mathrm{~K}$ on rifle skin signed by tournament MVP. Polygon. Retrieved from https://www.polygon.com/2018/ 1/30/16952248/counter-strike-global-offensivedragon-lore-skadoodle-skin-sale-opskins

Roth, C., \& Koenitz, H. (2019). Bandersnatch, yea or nay? Reception and user experience of an interactive digital narrative video. In Proceedings of the 2019 ACM International Conference on Interactive Experiences for TV and Online Video (pp. 247-254). Salford: Association for Computing Machinery. https://doi.org/ 10.1145/3317697.3325124

Shaw, A. (2010). What is video game culture? Cultural studies and game studies. Games and Culture, 5(4), 403-424. https://doi.org/10.1177/1555 412009360414

Shaw, A. (2012). Do you identify as a gamer? Gender, race, sexuality, and gamer identity. New Media \& Society, 14(1), 28-44. https://doi.org/10.1177/ 
1461444811410394

Sicart, M. (2011). Against procedurality. Game Studies, 11(3). Retrieved from http://gamestudies.org/1103/ articles/sicart_ap

Sicart, M. (2014). Play matters. Cambridge, MA: The MIT Press.

Brooker, C. (Writer), Slade, D. (Diretor). (2018). Black Mirror: Bandersnatch [Television series episode]. In Russell McLean (Executive producer), Black Mirror. London: House of Tomorrow, Netflix.

Sontag, S. (2001). Against interpretation, and other essays. New York, NY: Picador U.S.A. (Original work published 1966)

Star, S. L., \& Griesemer, J. R. (1989). Institutional ecology, 'translations' and boundary objects: Amateurs and professionals in Berkeley's museum of vertebrate zoology, 1907-39. Social Studies of Science, 19(3), 387-420. https://doi.org/10.1177/ 030631289019003001

Stenros, J., \& Kultima, A. (2018). On the expanding ludosphere. Simulation \& Gaming, 49(3), 338-355. https://doi.org/10.1177/1046878118779640

Stevenson, M. (2016). Rethinking the participatory web: A history of HotWired's "new publishing paradigm," 1994-1997. New Media \& Society, 18(7), 1331-1346. https://doi.org/10.1177/1461444814555950

Taylor, T. L. (2009). The assemblage of play. Games and Culture, 4(4), 331-339. https://doi.org/10.1177/ 1555412009343576
Taylor, T. L. (2018). Watch me play: Twitch and the rise of game live streaming. Princeton, NJ: Princeton University Press.

Voorhees, G. (2013). Criticism and control: Gameplay in the space of possibility. In M. Wysocki (Ed.), Ctrl-AltPlay: Essays on control in video gaming (pp. 9-20). Jefferson, NC: McFarland.

Vossen, E. (2018). On the cultural inaccessibility of gaming: Invading, creating, and reclaiming the cultural clubhouse. Waterloo: UWSpace. Retrieved from https://uwspace.uwaterloo.ca/handle/10012/ 13649

Wilmott, C., Fraser, E., \& Lammes, S. (2018). 'I am he. I am he. Siri rules': Work and play with the Apple watch. European Journal of Cultural Studies, 21(1), 78-95. https://doi.org/10.1177/1367549417705605

Wu, B. [@BriannaWu]. (2020, June 20). 1/ A highprofile journalist writing a book about online radicalization told me recently that all his research kept pointing back to Gamergate, and he regretted not taking it more seriously. I'd like you to imagine an alternate timeline where we. [Tweet]. Retrieved from: https://twitter.com/BriannaWu/status/12743 43193228840966

Zimmerman, E. (2015). Manifesto for a ludic century. In S. P. Walz \& S. Deterding (Eds.), The gameful world: Approaches, issues, applications (pp. 19-22). Boston, MA: The MIT Press. Retrieved from http://papers. ssrn.com/sol3/Papers.cfm?abstract_id=2463983

\section{About the Author}

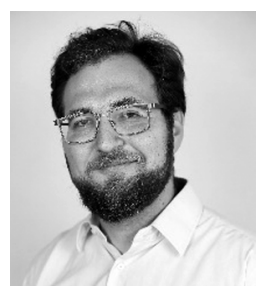

Alex Gekker is an Assistant Professor of New Media and Digital Culture at the University of Amsterdam. He writes on the ways in which sociotechnical systems are designed to influence users, and his research touches upon maps and surveillance, quantification and datafication of society, the experience economy and interface critique. He co-edited two Open Access books on mapping, one on temporality and the other on play. 